\title{
Determination of avidity of IgG against protein antigens from Streptococcus pneumoniae: assay development and preliminary application in clinical settings
}

\author{
D. C. Andrade ${ }^{1}$ - I. C. Borges ${ }^{1}$ • N. Ekström ${ }^{2}$ - T. Jartti ${ }^{3}$ - T. Puhakka ${ }^{4,5}$ - A. Barral ${ }^{6}$. \\ H. Kayhty ${ }^{2}$ - O. Ruuskanen ${ }^{3}$. C. M. Nascimento-Carvalho ${ }^{7}$
}

Received: 20 June 2017 / Accepted: 4 September 2017

(C) Springer-Verlag GmbH Germany 2017

\begin{abstract}
The measurement of antibody levels is a common test for the diagnosis of Streptococcus pneumoniae infection in research. However, the quality of antibody response, reflected by avidity, has not been adequately evaluated. We aimed to evaluate the role of avidity of IgG against eight pneumococcal proteins in etiologic diagnosis. Eight pneumococcal proteins (Ply, CbpA, PspA1 and 2, PcpA, PhtD, StkP$\mathrm{C}$, and PcsB-N) were used to develop a multiplex bead-based avidity immunoassay. The assay was tested for effects of the chaotropic agent, multiplexing, and repeatability. The developed assay was applied to paired samples from children with or without pneumococcal disease ( $n=38$ for each group), determined by either serology, polymerase chain reaction
\end{abstract}

D. C. Andrade

andradedafne@yahoo.com.br

1 Postgraduate Programme in Health Sciences, Federal University of Bahia School of Medicine, Salvador, Bahia, Brazil

2 National Institute for Health and Welfare, Helsinki, Finland

3 Department of Paediatrics, University of Turku and Turku University Hospital, Turku, Finland

4 Department of Otorhinolaryngology, University of Turku and Turku University Hospital, Turku, Finland

5 Department of Otorhinolaryngology, Satakunta Central Hospital, Pori, Finland

6 Pathology Department and Postgraduate Programme in Health Sciences, Federal University of Bahia School of Medicine and Centro de Pesquisa Gonçalo Muniz, Fundação Oswaldo Cruz, Salvador, Bahia, Brazil

7 Department of Pediatrics and Postgraduate Programme in Health Sciences, Federal University of Bahia School of Medicine, Salvador, Bahia, Brazil
(PCR), or blood culture. We found a good correlation between singleplex and multiplex assays, with $r \geq 0.94$. The assay was reproducible, with mean inter-assay variation $\leq 9 \%$ and intraassay variation $<6 \%$. Children with pneumococcal disease had lower median avidity indexes in the acute phase of disease for PspA1 and $2(p=0.042), \operatorname{PcpA}(p=0.002)$, PhtD $(p=0.014)$, and StkP-C $(p<0.001)$. When the use of IgG avidity as a diagnostic tool for pneumococcal infection was evaluated, the highest discriminative power was found for StkP-C, followed by PcpA (area under the curve [95\% confidence interval, CI]: 0.868 [0.759-0.977] and 0.743 [0.607879], respectively). The developed assay was robust and had no deleterious influence from multiplexing. Children with pneumococcal disease had lower median avidity against five pneumococcal proteins in the acute phase of disease compared to children without disease.

\section{Introduction}

Streptococcus pneumoniae is an important cause of morbidity and mortality in children worldwide [1]. The evaluation of the antibody response against capsular polysaccharides of this bacterium has been largely used as a tool for diagnostic purposes and to evaluate response to pneumococcal vaccines [2-4]. Over the past several decades, however, several new protein antigens from $S$. pneumoniae have been identified and recognized as specific and conserved antigens [5-7], suitable for use in diagnostic assays and experimental vaccines. Promising antigens include proteins involved in the pathogenesis of pneumococcal infections and which interact in many ways with the host immune system, such as pneumolysin (Ply), choline binding protein A (CbpA), pneumococcal surface protein $\mathrm{A}$ ( $\mathrm{PspA}$ ), pneumococcal choline binding protein A (PcpA), pneumococcal histidine triad protein D (PhtD), 
serine/threonine protein kinase (StkP), and protein required for cell wall separation of group B streptococcus (PcsB). Ply is a highly conserved cytotoxin released during autolysis $[6$, 7]; CbpA and PspA are choline binding proteins which share molecular similarities [6-10]; PcpA and PhtD are surface proteins which function as adhesins [11-13]; and StkP and PcsB are immunogenic proteins recently discovered, which are supposed to play roles in cell division and peptidoglycan metabolism, respectively [14-16]. Indeed, new vaccine formulations using the aforementioned pneumococcal proteins are being tested in both human and animal trials [17-19], and serological assays using these antigens are being developed and validated [20-22].

The antibody response against pneumococcal antigens is usually evaluated through the measurement of antigenspecific antibody levels. However, samples collected at different time points are required when the quantitation of antibodies is used for diagnostic purposes, representing a limitation of this method in the clinical setting. Therefore, assays able to evaluate the effectiveness of an antibody response using only one serum sample are warranted. The functionality of antibodies against a specific antigen reflects the quality of the immune response, and may be evaluated through antibody avidity assays [2]. Avidity represents the strength of antigen-antibody binding, and has been used as a diagnostic tool for viral infections [23, 24]. Furthermore, it has been reported to increase following exposure to $S$. pneumoniae [2, 25]. To date, the avidity of $\operatorname{IgG}$ antibodies against pneumococcal proteins has only been evaluated in a few studies, mostly experimental vaccine trials $[17,18]$. The objectives of this study were to validate a multiplex avidity assay using eight pneumococcal protein antigens, and to apply the developed assay to a clinical setting composed of children with and without pneumococcal disease with samples collected at admission and during convalescence.

\section{Materials and methods}

\section{Reagents}

A multiplexed avidity assay was designed using eight distinct recombinant pneumococcal protein antigens: Ply, CbpA, PspA family 1 (PspA1), PspA family 2 (PspA2), PcpA, PhtD, StkP-C (a C-terminal fragment of StkP), and PcsB-N (an N-terminal fragment of PcsB). A truncated PcpA [26] and PhtD [27] were supplied by Sanofi Pasteur (Sanofi Pasteur S.A., Marcy-L'Etoile, France); Ply [28], CbpA [29], and PspA1 (UAB055) [8] were supplied by Prof. Elaine Tuomanen at St. Judes Children's Research Hospital (Memphis, TN, USA); PspA 2 was supplied by Pat Coan and Profs. Susan Hollingshead and David Briles at the University of Alabama (Birmingham, AL, USA); and StkP-
$\mathrm{C}$ and PcsB-N were supplied by Valneva Austria GmbH (Vienna, Austria) [14]. Protein antigens included in this assay were chosen based on previous data on immunogenicity profiles [6-14] and natural development of antibodies [30].

Hydroxysulfosuccinimide (Sulfo-NHS) and 1-ethyl-3-(3dimethylaminopropyl)carbodiimide hydrochloride (EDC) were obtained from Thermo Fisher Scientific, Rockford, IL, USA. R-phycoerythrin (R-PE)-conjugated AffiniPure Goat Anti-Human $\mathrm{IgG} \mathrm{Fc}_{\gamma}$ Fragment Specific was obtained from Jackson ImmunoResearch Laboratories, Inc. (Westgrove, PA, USA). Sodium thiocyanate $98 \%$ was obtained from SigmaAldrich (St. Louis, MO, USA). Carboxylated MicroPlex beads were obtained from Luminex Corporation (Austin, TX, USA). Fetal bovine serum was obtained from Life Technologies (Paisley, UK).

\section{Serum samples}

Patient sera that had been sent to the National Institute for Health and Welfare (Helsinki, Finland) for antibody testing were used without identification for optimization of the avidity assay, evaluation of the effect of Sodium thiocyanate on the antigen-conjugated beads, and to assess the optimal range of fluorescence readings for the determination of avidity indexes. Thirteen paired samples from Brazilian children with invasive pneumococcal disease (IPD) determined by either blood culture ( 9 cases) or blood polymerase chain reaction (PCR) using the ply primer (4 cases) were used as pneumococcal patients [20]. Paired samples from 13 healthy Finnish children who were submitted to elective tonsillectomy were used as nonpneumococcal patients [20]. Finally, the developed avidity assay was used to test paired samples from 50 children with non-bacteremic community-acquired pneumonia (CAP), which were selected based on the adequacy of the fluorescence readings for avidity testing. Out of these 50 patients, 25 had increases in anti-protein-specific IgG between acute and convalescent samples and 25 failed to respond to any of the studied pneumococcal antigens. The presence of serological response was defined as $a \geq 2$-fold increase in the antibody levels for IgG against Ply, CbpA, PspA1 and 2, PhtD, StkP-C, or PcsB-N, or a $\geq 1.5$-fold increase in the antibody levels for IgG against PcpA [20]. The flow chart for the patients whose samples were tested in this study is shown in Fig. 1. All the samples evaluated for avidity were from patients aged 1 to 57 months, out of which 5 patients were less than 6 months of age.

The use of the samples was approved by the Ethics Committee of the Federal University of Bahia in Brazil, the Ethics Committee of the National Institute for Health and Welfare in Finland (formerly National Public Health Institute), and the Ethics Committee of Satakunta Central Hospital, Pori, Finland. 
Fig. 1 Flow chart of the samples analyzed in this study

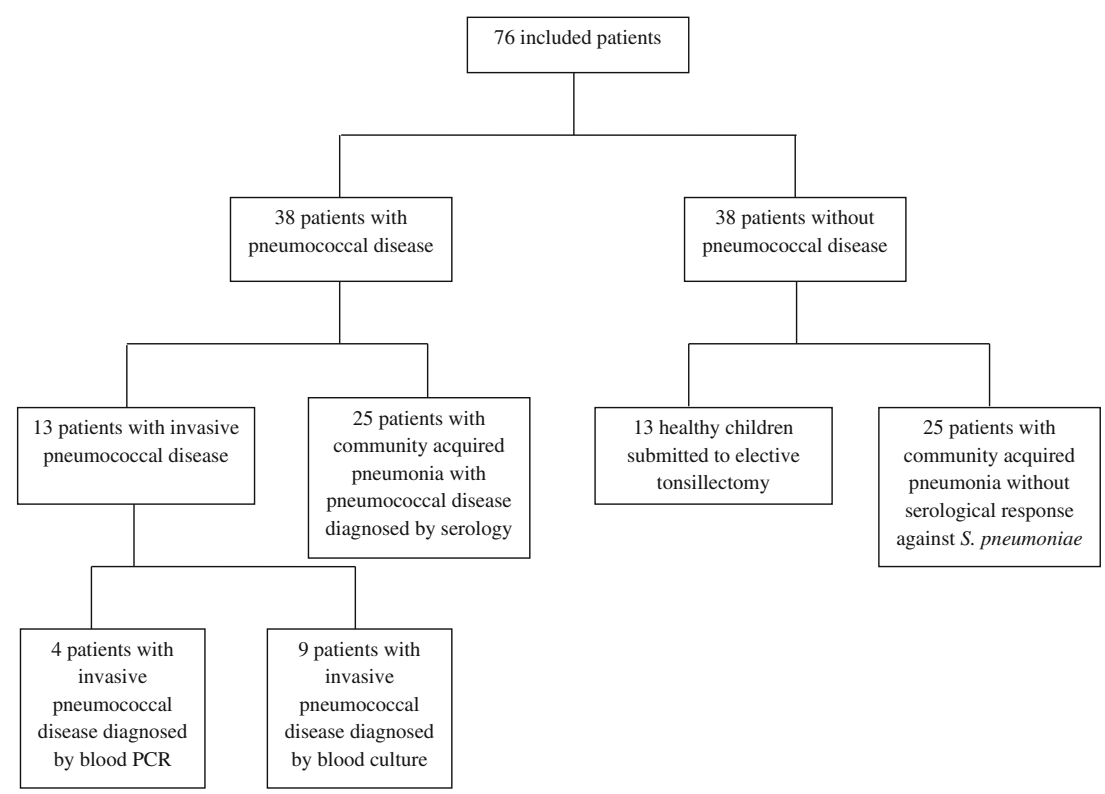

\section{Coupling of proteins to the beads and serologic assay}

A multiplexed bead-based serologic assay using Luminex xMAP® Technology to determine the levels of anti-proteinspecific IgG was performed as previously described [21]. Pneumococcal proteins were coupled to activated carboxylated MicroPlex beads by a two-step carbodiimide reaction [20, 21]. Each pneumococcal protein was conjugated in one bead set, except for PspA1 and 2, which were conjugated mixed on the same bead set. Samples were analyzed using a Luminex 200 device and software (xMAP® Technology, Luminex Corporation, Austin, TX, USA).

\section{Avidity assay}

Initially, $25 \mu \mathrm{L}$ of the F-PBS diluted serum sample in 12 replicates and $25 \mu \mathrm{L}$ of beads diluted in F-PBS were transferred to each well of a 96-well plate (Millipore MSHVN4510, Merck KGaA, Darmstadt, Germany). Samples were diluted from 1:100 up to 1:6400, aiming to create fluorescence readings on the optimal range for the avidity assay. The plate was then incubated on a shaker at $900 \mathrm{rpm}$ for $1 \mathrm{~min}$ and $600 \mathrm{rpm}$ for $60 \mathrm{~min}$ at room temperature in the dark. After incubation, the plate was washed twice with PBS using a vacuum washer, and $25 \mu \mathrm{L}$ of a solution of the chaotropic agent (Sodium thiocyanate in PBS) at six different concentrations was added: $0,0.5,1,2,4$, and $6 \mathrm{M}$. The mixture was incubated for $15 \mathrm{~min}$ at $600 \mathrm{rpm}$ in the dark and the plate was washed twice with PBS using a vacuum washer. Finally, $50 \mu \mathrm{L}$ of a $1 / 100$ dilution of R-PE conjugated antihuman IgG in PBS was added and the plate was incubated at $900 \mathrm{rpm}$ for $1 \mathrm{~min}$ and $600 \mathrm{rpm}$ for $30 \mathrm{~min}$ at room temperature. The plate was then washed as above and $80 \mu \mathrm{L} /$ well of PBS was added. True duplicates were used throughout the development of this protocol and the median fluorescence intensity (MFI) values were averaged. The avidity index was calculated as the molar concentration of Sodium thiocyanate required to elute $50 \%$ of the bound specific antibody in a given sample $[2,3,31]$.

\section{Determination of the effect of Sodium thiocyanate on conjugated beads}

Beads conjugated with each of the studied antigens were tested for the effect of a $6 \mathrm{M}$ solution of Sodium thiocyanate in PBS to ensure that Sodium thiocyanate does not disrupt the antigenic structures of the antigens. A quantity of $25 \mu \mathrm{L}$ of bead solution was incubated with either $25 \mu \mathrm{L}$ of a $6 \mathrm{M}$ Sodium thiocyanate solution or PBS for $15 \mathrm{~min}$ at $600 \mathrm{rpm}$ in the dark. After incubation, the plate was washed twice with a vacuum washer and serial 1:4 dilutions of a serum sample with high levels of $\mathrm{IgG}$ against the evaluated antigens was added and the assay proceeded as described previously [21].

\section{Determination of the optimal range of fluorescence for avidity testing}

Samples with a distinct range of MFI for all the studied antigens were assayed for avidity as previously described. Seven serial 1:4 dilutions from two serum samples were assayed for avidity. The avidity index for each sample dilution was calculated and the range of MFI that yielded consistent avidity indexes was determined. 

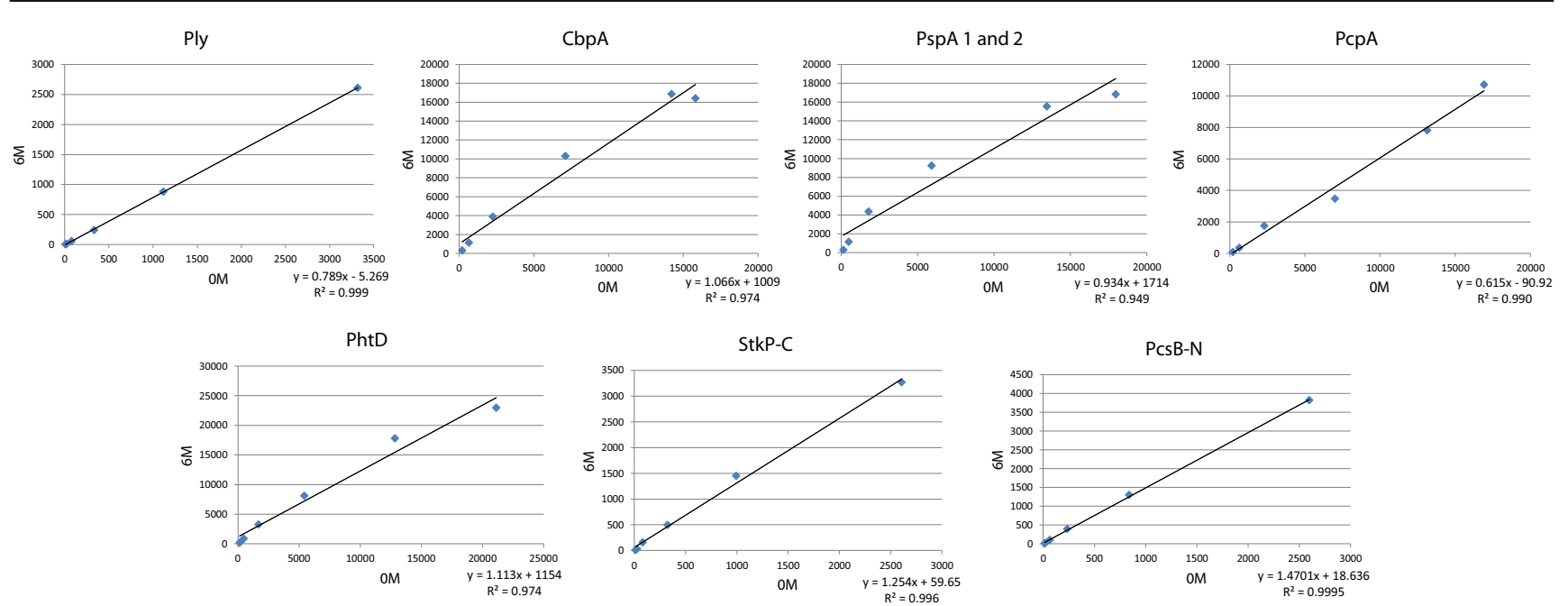

Fig. 2 Correlation between the median fluorescence intensity (MFI) values elicited by seven serial 1:4 dilutions of a serum sample with beads submitted or not to a pretreatment with $6 \mathrm{M}$ Sodium thiocyanate

\section{Comparison of singleplex and multiplex assays}

The comparability between the single- and multiplex avidity assays was evaluated by determining the avidity index for a sample with high values of anti-protein $\operatorname{IgG}$ for all studied antigens by both formats.

\section{Repeatability}

Repeatability of the avidity assay was assessed by determining both intra- and inter-assay variation for each antigen. Intra-assay variation was calculated from eight repetitions of one sample in the same plate. Inter-assay variation was calculated from the results of two repetitions of eight samples of Brazilian children with CAP on different days. The percentage coefficient of variation $(\mathrm{CV})$ was calculated for each of these results and averaged.

\section{Evaluation of avidity in clinical settings}

The avidity of IgG against pneumococcal proteins was evaluated in paired serum samples from 13 children with IPD (positive cases), 13 healthy children (negative cases), and 50 children with non-invasive CAP (25 with and 25 without serological response against $S$. pneumoniae). The avidity indexes were compared based on the group of analysis and time of sample collection (acute or convalescent samples, collected 2-4 weeks apart).

\section{Statistical analysis}

Categorical variables were presented as absolute number (percentage) and continuous variables as median (25th-75th percentiles), as they showed non-parametric distributions. Categorical variables were compared using the Chi-square or
Fisher's exact test as appropriate, and continuous variables were evaluated using the Mann-Whitney $U$-test. Comparison between samples collected at different time points was performed using the Wilcoxon signed-rank test. Receiver operating characteristic (ROC) curves were plotted to determine the accuracy of avidity of IgG against pneumococcal proteins in differentiating children with or without pneumococcal disease, using either each antigen individually or combinations of different antigens. All statistical tests were two-tailed (significance level of 0.05) using SPSS software (version 9.0).

\section{Results}

\section{Optimization of the avidity assay}

\section{Determination of the effect of Sodium thiocyanate on conjugated beads}

The comparison between beads pretreated with $6 \mathrm{M}$ solution of Sodium thiocyanate or PBS is shown in Fig. 2. Overall, the chaotropic agent did not have an effect on the antigens that would inhibit the binding of IgG to most conjugated beads, and similar fluorescence readings were obtained with or without treatment with Sodium thiocyanate. A decrease in the fluorescence readings was found solely for beads conjugated with PcpA. Nevertheless, we still found a good correlation between fluorescence readings obtained with or without treatment with Sodium thiocyanate for all the studied antigens, with a corresponding correlation coefficient $\geq 0.97$ for all of them. Also, no difference was found when the fluorescence readings from pretreated beads with $6 \mathrm{M}$ solution of Sodium thiocyanate or PBS were compared (data not shown). There was no effect from the thiocyanate treatment on background MFI levels (data not shown). 
Table 1 Number of considered samples for avidity analysis, based on the presence of fluorescence readings included in the established range (median fluorescence intensity [ (MFI] ranging from 100 to 7000)

\begin{tabular}{|c|c|c|c|c|}
\hline & $\begin{array}{l}\text { Invasive } \\
\text { pneumococcal } \\
\text { disease }(n=13)\end{array}$ & $\begin{array}{l}\text { Healthy } \\
\text { children } \\
(n=13)\end{array}$ & $\begin{array}{l}\text { Children with } \\
\text { serological } \\
\text { response }(n=25)\end{array}$ & $\begin{array}{l}\text { Children without } \\
\text { serological } \\
\text { response }(n=25)\end{array}$ \\
\hline \multicolumn{5}{|l|}{ Ply } \\
\hline First serum sample & $13(100 \%)$ & $12(92 \%)$ & $25(100 \%)$ & $25(100 \%)$ \\
\hline Second serum sample & $12(92 \%)$ & $12(92 \%)$ & $25(100 \%)$ & $25(100 \%)$ \\
\hline Number of pairs & $12(92 \%)$ & $12(92 \%)$ & $25(100 \%)$ & $25(100 \%)$ \\
\hline \multicolumn{5}{|l|}{ CbpA } \\
\hline First serum sample & $12(92 \%)$ & $9(69 \%)$ & $17(68 \%)$ & $16(64 \%)$ \\
\hline Second serum sample & $12(92 \%)$ & $9(69 \%)$ & $19(76 \%)$ & $17(68 \%)$ \\
\hline Number of pairs & $12(92 \%)$ & $8(61 \%)$ & $13(52 \%)$ & $15(60 \%)$ \\
\hline \multicolumn{5}{|l|}{ PspA1 and 2} \\
\hline First serum sample & $11(85 \%)$ & $10(77 \%)$ & $22(88 \%)$ & $22(88 \%)$ \\
\hline Second serum sample & $11(85 \%)$ & $9(69 \%)$ & $21(84 \%)$ & $22(88 \%)$ \\
\hline Number of pairs & $10(77 \%)$ & $9(69 \%)$ & $19(76 \%)$ & $20(80 \%)$ \\
\hline \multicolumn{5}{|l|}{ PcpA } \\
\hline First serum sample & $7(54 \%)$ & $11(85 \%)$ & $17(68 \%)$ & $20(80 \%)$ \\
\hline Second serum sample & $7(54 \%)$ & $11(85 \%)$ & $10(40 \%)$ & $19(76 \%)$ \\
\hline Number of pairs & $5(38 \%)$ & $10(77 \%)$ & $7(28 \%)$ & $18(72 \%)$ \\
\hline \multicolumn{5}{|l|}{ PhtD } \\
\hline First serum sample & $12(92 \%)$ & $12(92 \%)$ & $21(84 \%)$ & $21(84 \%)$ \\
\hline Second serum sample & $13(100 \%)$ & $11(85 \%)$ & $20(80 \%)$ & $20(80 \%)$ \\
\hline Number of pairs & $12(92 \%)$ & $11(85 \%)$ & $19(76 \%)$ & $19(76 \%)$ \\
\hline \multicolumn{5}{|l|}{ StkP-C } \\
\hline First serum sample & $3(23 \%)$ & $8(62 \%)$ & $13(52 \%)$ & $16(64 \%)$ \\
\hline Second serum sample & $1(8 \%)$ & $7(54 \%)$ & $10(40 \%)$ & $18(72 \%)$ \\
\hline Number of pairs & $1(8 \%)$ & $7(54 \%)$ & $7(28 \%)$ & $16(64 \%)$ \\
\hline \multicolumn{5}{|l|}{ PcsB-N } \\
\hline First serum sample & $13(100 \%)$ & $11(85 \%)$ & $22(88 \%)$ & $23(92 \%)$ \\
\hline Second serum sample & $11(85 \%)$ & $11(85 \%)$ & $23(92 \%)$ & $23(92 \%)$ \\
\hline Number of pairs & $11(85 \%)$ & $11(85 \%)$ & $21(84 \%)$ & $22(88 \%)$ \\
\hline
\end{tabular}

Determination of the optimal range of fluorescence for avidity testing

The developed avidity assay gave consistent results in the MFI range from 100 up to 7000, with the coefficient of variation ranging from $1 \%$ for Ply up to $12 \%$ for PcpA. Higher values presented greater variability in the avidity index, and lower values were often out of the linear range of the serologic assay [21]. Values outside the determined linear range were excluded from the analysis. The number of samples included in the avidity analysis is shown in Table 1.

\section{Comparison of singleplex and multiplex assays}

We found good correlation between avidity indexes determined by the singleplex and multiplex assays, with a correlation coefficient $\geq 0.94$ for all the studied antigens, as shown in
Fig. 3. Therefore, multiplexing did not have an effect on the results of the developed avidity assay.

\section{Repeatability}

The developed avidity assay had good robustness regarding inter- and intra-assay variation. The intra-assay variation ranged from $0 \%$ for PcpA up to $6 \%$ for Ply, and the interassay variation ranged from $2 \%$ for CbpA up to $9 \%$ for PspA1 and 2 (data not shown).

\section{Determination of IgG avidity in clinical settings}

This study included 76 children whose median age was 19 months ([25th-75th percentile]: $12-32$ months) and the median interval of serum sample collection was 21 days 


\section{Comparison of Avidity Index}

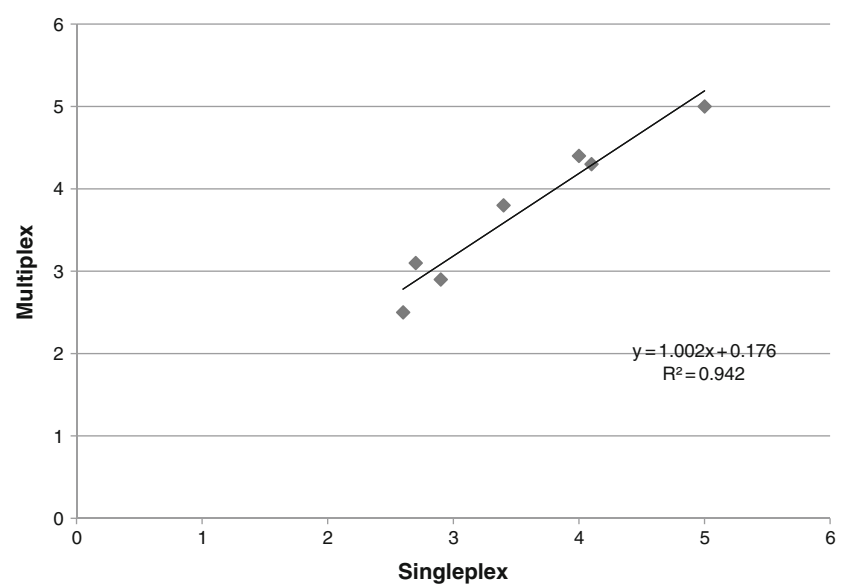

Fig. 3 Comparison of the avidity index from seven bead sets assayed in the singleplex and multiplex assays

([25th-75th percentile]: 17-32 days). Children with pneumococcal disease diagnosed by either serology, blood culture, or blood PCR had samples collected within a shorter time interval (median [25th-75th percentile]: 20 [17-25] vs. 23 [18-41] days; $p=0.011$ ) when compared to the group of children without pneumococcal disease (including healthy children and children with CAP without serological response to S. pneumoniae), but there was no statistical difference in age (median [25th-75th percentile]: 16 [10-28] vs. 24 [14-39] months; $p=0.054)$. When evaluating solely the group of children without pneumococcal disease, children with CAP without serological response to $S$. pneumoniae were younger (median [25th-75th percentile]: 18 [12-30] vs. 29 [23-46] months; $p=0.016$ ) and had samples collected at a shorter time interval (median [25th-75th percentile]: 19 [17-23] vs. 44 [40-52] days; $p<0.001$ ) when compared to the subgroup of healthy children submitted to elective tonsillectomy (negative cases). There was no difference in age and sampling interval between children with IPD and children with CAP and serological response against $S$. pneumoniae (data not shown).

Initially, we compared the IgG avidity elicited in children with IPD and healthy children submitted to elective tonsillectomy, as shown in Table 2. In children with IPD, lower median IgG avidity than in healthy children was found in the acute phase for PcpA, PhtD, and PcsB-N. In the convalescent phase,

Table 2 Comparison of the avidity index obtained from children with invasive pneumococcal disease (positive cases) and healthy children submitted to elective tonsillectomy (negative cases), on the acute and convalescent serum samples

\begin{tabular}{|c|c|c|c|c|c|c|}
\hline \multirow[t]{2}{*}{ Antigen } & \multicolumn{3}{|c|}{ Acute serum sample } & \multicolumn{3}{|c|}{ Convalescent serum sample } \\
\hline & $\begin{array}{l}\text { Invasive } \\
\text { pneumococcal } \\
\text { disease }(n=13)^{\mathrm{a}}\end{array}$ & $\begin{array}{l}\text { Healthy } \\
\text { children } \\
(n=13)\end{array}$ & $p$-Value & $\begin{array}{l}\text { Invasive } \\
\text { pneumococcal } \\
\text { disease }(n=13)^{\mathrm{a}}\end{array}$ & $\begin{array}{l}\text { Healthy } \\
\text { children } \\
(n=13)\end{array}$ & $p$-Value \\
\hline Ply & $4.6(2.7-5.8)$ & $4(3.8-4.8)$ & $0.810^{\mathrm{c}}$ & $4.3(3.2-6.5)$ & $3.9(3.7-4.4)$ & $0.755^{\mathrm{i}}$ \\
\hline CbpA & $2.4(1.9-2.7)$ & $2.8(2.5-3)$ & $0.082^{\mathrm{d}}$ & $2.5(1.4-2.8)$ & $2.8(2.4-2.8)$ & $0.277^{\mathrm{j}}$ \\
\hline PspA1 and 2 & $0.8(0.4-1.3)$ & $1.2(0.8-1.5)$ & $0.173^{\mathrm{e}}$ & $0.6(0.4-1)$ & $0.9(0.7-1.6)$ & $0.131^{\mathrm{k}}$ \\
\hline PcpA & $1.3(0.4-1.4)$ & $1.5(1.4-2)$ & $0.006^{\mathrm{f}}$ & $1.4(0.8-1.5)$ & $1.5(1.3-1.9)$ & $0.104^{1}$ \\
\hline PhtD & $2.2(1.9-3.6)$ & $4.2(3.4-4.4)$ & $0.001^{\mathrm{g}}$ & $2.5(1.5-3.1)$ & $4.4(3.6-4.5)$ & $<0.001^{\mathrm{m}}$ \\
\hline StkP-C ${ }^{b}$ & - & - & - & $2.2(2.2-2.2)$ & $3.2(2.6-4)$ & $0.250^{\mathrm{n}}$ \\
\hline PcsB-N & $1.8(1.1-2.4)$ & $3(2.2-3.4)$ & $0.035^{\mathrm{h}}$ & $2.1(1.5-2.5)$ & $3(2-3.3)$ & $0.034^{\circ}$ \\
\hline
\end{tabular}

${ }^{\mathrm{a}}$ Invasive pneumococcal disease: 9 patients with positive blood culture and 4 patients with positive blood PCR

${ }^{b}$ Data from the first serum sample from the group with invasive pneumococcal disease was not considered for the analysis due to insufficient sampling

${ }^{\mathrm{c}}$ Number of included samples: 25

${ }^{\mathrm{d}}$ Number of included samples: 21

${ }^{\mathrm{e}}$ Number of included samples: 21

${ }^{\mathrm{f}}$ Number of included samples: 18

${ }^{\mathrm{g}}$ Number of included samples: 24

${ }^{\mathrm{h}}$ Number of included samples: 24

${ }^{\mathrm{i}}$ Number of included samples: 24

${ }^{\mathrm{j}}$ Number of included samples: 21

${ }^{\mathrm{k}}$ Number of included samples: 20

${ }^{1}$ Number of included samples: 18

${ }^{\mathrm{m}}$ Number of included samples: 24

${ }^{\mathrm{n}}$ Number of included samples: 8

${ }^{\mathrm{o}}$ Number of included samples: 22 
Table 3 Comparison of the avidity indexes between children with pneumococcal disease diagnosed by either blood PCR and blood culture (invasive pneumococcal disease) or serology

\begin{tabular}{|c|c|c|c|c|c|c|}
\hline \multirow[t]{2}{*}{ Antigen } & \multicolumn{3}{|c|}{ Acute serum sample } & \multicolumn{3}{|c|}{ Convalescent serum sample } \\
\hline & $\begin{array}{l}\text { Invasive } \\
\text { pneumococcal } \\
\text { disease }(n=13)^{\mathrm{a}}\end{array}$ & $\begin{array}{l}\text { Serology } \\
(n=25)\end{array}$ & $p$-Value & $\begin{array}{l}\text { Invasive } \\
\text { pneumococcal } \\
\text { disease }(n=13)^{\mathrm{a}}\end{array}$ & $\begin{array}{l}\text { Serology } \\
(n=25)\end{array}$ & $p$-Value \\
\hline Ply & $4.6(2.7-5.8)$ & $4.2(3.6-5.2)$ & $0.584^{\mathrm{c}}$ & $4.3(3.2-6.5)$ & $3.9(2.9-5.5)$ & $0.532^{\mathrm{i}}$ \\
\hline CbpA & $2.4(1.9-2.7)$ & $2.6(2.2-2.9)$ & $0.325^{\mathrm{d}}$ & $2.5(1.4-2.8)$ & $2.5(0.9-2.8)$ & $0.562^{\mathrm{j}}$ \\
\hline PspA1 and 2 & $0.8(0.4-1.3)$ & $1.2(0.6-1.9)$ & $0.317^{\mathrm{e}}$ & $0.6(0.4-1)$ & $1(0.4-2.2)$ & $0.271^{\mathrm{k}}$ \\
\hline PcpA & $1.3(0.4-1.4)$ & $1.1(0.6-1.7)$ & $0.455^{\mathrm{f}}$ & $1.4(0.8-1.5)$ & $1.7(1.1-2.2)$ & $0.109^{1}$ \\
\hline $\mathrm{PhtD}$ & $2.2(1.9-3.6)$ & $3(2.4-3.8)$ & $0.385^{\mathrm{g}}$ & $2.5(1.5-3.1)$ & $2.8(1.7-3.3)$ & $0.456^{\mathrm{m}}$ \\
\hline StkP-C ${ }^{b}$ & - & - & - & $2.2(2.2-2.2)$ & $3(1.9-3.3)$ & $0.545^{\mathrm{n}}$ \\
\hline PcsB-N & $1.8(1.1-2.4)$ & $2.5(1.7-3.1)$ & $0.180^{\mathrm{h}}$ & $2.1(1.5-2.5)$ & $2.7(1.8-3.1)$ & $0.201^{\mathrm{o}}$ \\
\hline
\end{tabular}

${ }^{\mathrm{a}}$ Invasive pneumococcal disease: 9 patients with positive blood culture and 4 patients with positive blood PCR

${ }^{b}$ Data from the first serum sample from the group with invasive pneumococcal disease was not considered for the analysis due to insufficient sampling

${ }^{\mathrm{c}}$ Number of included samples: 38

${ }^{\mathrm{d}}$ Number of included samples: 29

${ }^{\text {e }}$ Number of included samples: 33

${ }^{\mathrm{f}}$ Number of included samples: 24

${ }^{g}$ Number of included samples: 33

${ }^{\mathrm{h}}$ Number of included samples: 35

${ }^{\mathrm{i}}$ Number of included samples: 37

${ }^{\mathrm{j}}$ Number of included samples :31

${ }^{\mathrm{k}}$ Number of included samples: 32

${ }^{1}$ Number of included samples: 17

${ }^{\mathrm{m}}$ Number of included samples: 33

${ }^{\mathrm{n}}$ Number of included samples: 11

${ }^{\circ}$ Number of included samples: 34

lower IgG avidity in the group with IPD than in healthy children was found for PhtD and PcsB-N.

Subsequently, we compared the IgG avidity indexes within the groups of children with and without pneumococcal disease. We found no difference in either acute or convalescent samples between children with pneumococcal disease diagnosed by blood PCR and blood culture or serology, as shown in Table 3. On the comparison of healthy children submitted to elective tonsillectomy and children with CAP without serological response to $S$. pneumoniae, we found that children with pneumonia had a lower median IgG avidity index against PhtD in both acute and convalescent samples. These results are shown in Table 4.

When evaluating the $\operatorname{IgG}$ avidity indexes from children with pneumococcal disease diagnosed by either serology, culture, or PCR and children without pneumococcal disease (including healthy children and children with CAP without serological response to $S$. pneumoniae), we found that children with pneumococcal disease had lower median IgG avidity indexes in both acute and convalescent samples, as shown in Table 5. The IgG avidity indexes for PspA1 and 2, PcpA,
$\mathrm{PhtD}$, and StkP-C were significantly lower in the acute sample for the group with pneumococcal disease. On the convalescent phase, significantly lower IgG avidity was found for CbpA, PspA1 and 2, PhtD, StkP-C, and PcsB-N.

There was no difference in the median IgG avidity index between acute and convalescent samples in children with and without pneumococcal disease (data not shown). A modest increase in IgG avidity between acute and convalescent samples was found among children with pneumococcal disease for PcpA (1.4 [0.9-1.8] vs. 1.5 [0.8-1.7]; $p=0.250)$, StkP-C (2.5 [1.3-3] vs. $3.1[1-3.4] ; p=0.236)$, and PcsB-N (2.30 $[1.6-3.1]$ vs. $2.35[1.6-3] ; p=0.204)$.

\section{Evaluation of diagnostic applications for IgG avidity}

The ROC curves for PspA1 and 2, PcpA, PhtD, and StkP-C are shown in Fig. 4, as well as the number of values included in the analysis, and the accuracy, specificity, and sensitivity of the cut-offs for each antigen. The optimal cut-off points were chosen based on the highest accuracy for each antigen. 
Table 4 Comparison of the avidity indexes between children without pneumococcal disease from the subgroups of healthy children submitted to elective tonsillectomy and children with community-acquired pneumonia without serological response against $S$. pneumoniae

\begin{tabular}{|c|c|c|c|c|c|c|}
\hline \multirow[t]{2}{*}{ Antigen } & \multicolumn{3}{|c|}{ Acute serum sample } & \multicolumn{3}{|c|}{ Convalescent serum sample } \\
\hline & $\begin{array}{l}\text { Healthy } \\
\text { children } \\
(n=13)\end{array}$ & $\begin{array}{l}\text { Children without } \\
\text { serological } \\
\text { response }(n=25)\end{array}$ & $p$-Value & $\begin{array}{l}\text { Healthy } \\
\text { children } \\
(n=13)\end{array}$ & $\begin{array}{l}\text { Children without } \\
\text { serological } \\
\text { response }(n=25)\end{array}$ & $p$-Value \\
\hline Ply & $4(3.8-4.8)$ & $3.9(3.4-4.8)$ & $0.451^{\mathrm{a}}$ & $3.9(3.7-4.4)$ & $4.4(3.3-5.3)$ & $0.936^{\mathrm{h}}$ \\
\hline CbpA & $2.8(2.5-3)$ & $2.7(2.5-2.8)$ & $0.388^{\mathrm{b}}$ & $2.8(2.4-2.8)$ & $2.7(2.5-2.8)$ & $0.958^{\mathrm{i}}$ \\
\hline PspA1 and 2 & $1.2(0.8-1.5)$ & $1.6(1.1-2.4)$ & $0.084^{\mathrm{c}}$ & $0.9(0.7-1.6)$ & $1.4(1-2.3)$ & $0.086^{\mathrm{j}}$ \\
\hline PcpA & $1.5(1.4-2)$ & $1.6(1.3-1.9)$ & $1^{\mathrm{d}}$ & $1.5(1.3-1.9)$ & $1.7(1.4-2.1)$ & $0.445^{\mathrm{k}}$ \\
\hline PhtD & $4.2(3.4-4.4)$ & $3.2(2.7-3.7)$ & $0.002^{\mathrm{e}}$ & $4.4(3.6-4.5)$ & $3.2(2.6-3.7)$ & $0.001^{1}$ \\
\hline StkP-C & $3.2(2.8-4.3)$ & $3.5(3.1-4.1)$ & $0.653^{\mathrm{f}}$ & $3.2(2.6-4)$ & $3.5(3.1-4)$ & $0.357^{\mathrm{m}}$ \\
\hline PcsB-N & $3(2.2-3.4)$ & $2.7(2-3.1)$ & $0.445^{\mathrm{g}}$ & $3(2-3.3)$ & $2.9(2.4-3.1)$ & $0.561^{\mathrm{n}}$ \\
\hline
\end{tabular}

${ }^{\text {a }}$ Number of included samples: 37

${ }^{\mathrm{b}}$ Number of included samples: 25

${ }^{\mathrm{c}}$ Number of included samples: 32

${ }^{\mathrm{d}}$ Number of included samples: 31

${ }^{\text {e }}$ Number of included samples: 33

${ }^{f}$ Number of included samples: 24

${ }^{g}$ Number of included samples: 34

${ }^{\mathrm{h}}$ Number of included samples: 37

${ }^{\mathrm{i}}$ Number of included samples: 26

${ }^{\mathrm{j}}$ Number of included samples: 31

${ }^{\mathrm{k}}$ Number of included samples: 30

${ }^{1}$ Number of included samples: 31

${ }^{\mathrm{m}}$ Number of included samples: 25

${ }^{\mathrm{n}}$ Number of included samples: 34

The highest discriminative power was found for StkP-C, followed by PcpA. The area under the curve varied from 0.65 up to 0.85 , and the optimal cut-offs of avidity for the diagnosis of pneumococcal disease were: $<0.9$ for PspA1 and $2,<1.2$ for PcpA, $<3.1$ for PhtD, and $<2.8$ for StkP-C. Similar results were obtained when the ROC curves were plotted considering children with pneumococcal disease diagnosed by either serology, blood culture, or PCR as positive cases and solely the group of children with CAP without serological response against $S$. pneumoniae as negative cases (data not shown). Finally, there was an increase in the accuracy of IgG avidity for the diagnosis of pneumococcal disease by combining the avidity indexes against PcpA and StkP-C, as shown in Fig. 5, with an area under the curve of 0.871 (95\% CI: 0.8-0.942). The comparison of the median difference between acute and convalescent samples for all antigens is shown in Fig. 6 .

\section{Discussion}

In this report, we describe the development and validation of a multiplex avidity assay using pneumococcal proteins. When the assay was applied to a clinical setting, we found that children with pneumococcal infection present lower median avidity of IgG against protein antigens when compared to children without evidence of pneumococcal infection. Furthermore, data from the ROC curve analysis suggest that avidity studies might be useful as a diagnostic tool requiring serum sample collection only in the acute phase of disease.

The avidity of IgG against pneumococcal polysaccharides has been largely studied in vaccine trials, as a tool to evaluate the quality of the antibody response [3, 32]. Avidity tests may be used as a measure of functionality of the antibody response, and a negative correlation between antibody avidity and the antibody concentration required for opsonophagocytic/ bactericidal activity has been reported in previous studies [33-35]. The use of avidity to evaluate antibody response against pneumococcal proteins, however, has only been used in a few studies, mostly experimental vaccine trials with animal models $[17,18]$. Therefore, in the current setting, where new vaccines using protein antigens are under development [19], the validation of cost-effective protocols to evaluate the avidity of $\operatorname{IgG}$ against protein antigens is warranted. Herein, we described the validation of a robust avidity assay, in which 
Table 5 Comparison of the avidity index obtained from children with and without pneumococcal disease on the acute and convalescent serum samples

\begin{tabular}{|c|c|c|c|c|c|c|}
\hline \multirow[t]{2}{*}{ Antigen } & \multicolumn{3}{|c|}{ Acute serum sample } & \multicolumn{3}{|c|}{ Convalescent serum sample } \\
\hline & $\begin{array}{l}\text { Pneumococcal } \\
\text { disease } \\
(n=38)\end{array}$ & $\begin{array}{l}\text { No } \\
\text { pneumococcal } \\
\text { disease }(n=38)\end{array}$ & $p$-Value & $\begin{array}{l}\text { Pneumococcal } \\
\text { disease }(n=38)\end{array}$ & $\begin{array}{l}\text { No } \\
\text { pneumococcal } \\
\text { disease }(n=38)\end{array}$ & $p$-Value \\
\hline Ply & $4.2(3.3-5.5)$ & $4(3.5-4.8)$ & $0.611^{\mathrm{a}}$ & $3.9(3.1-5.6)$ & $4(3.5-4.7)$ & $0.965^{\mathrm{h}}$ \\
\hline CbpA & $2.6(2.1-2.9)$ & $2.7(2.5-2.9)$ & $0.150^{\mathrm{b}}$ & $2.5(1.2-2.8)$ & $2.7(2.5-2.8)$ & $0.034^{\mathrm{i}}$ \\
\hline PspA1 and 2 & $1(0.5-1.7)$ & $1.4(0.9-2.1)$ & $0.042^{\mathrm{c}}$ & $0.9(0.4-1.7)$ & $1.4(0.9-2.1)$ & $0.026^{\mathrm{j}}$ \\
\hline PсрA & $1.2(0.6-1.5)$ & $1.5(1.4-1.9)$ & $0.002^{\mathrm{d}}$ & $1.5(1-1.8)$ & $1.65(1.4-1.9)$ & $0.148^{\mathrm{k}}$ \\
\hline PhtD & $3(1.9-3.7)$ & $3.4(2.9-4.1)$ & $0.014^{\mathrm{e}}$ & $2.7(1.7-3.3)$ & $3.6(3.1-4.2)$ & $<0.001^{1}$ \\
\hline StkP-C & $2.7(1.4-3.1)$ & $3.45(3-4.1)$ & $<0.001^{\mathrm{f}}$ & $3(2.2-3.3)$ & $3.5(3-4)$ & $0.011^{\mathrm{m}}$ \\
\hline PcsB-N & $2.2(1.5-3.1)$ & $2.75(2.1-3.1)$ & $0.072^{\mathrm{g}}$ & $2.3(1.6-3)$ & $2.9(2.4-3.2)$ & $0.037^{\mathrm{n}}$ \\
\hline
\end{tabular}

${ }^{a}$ Number of included samples: 75

${ }^{\mathrm{b}}$ Number of included samples: 54

${ }^{\mathrm{c}}$ Number of included samples: 65

${ }^{\mathrm{d}}$ Number of included samples: 55

${ }^{\text {e }}$ Number of included samples: 66

${ }^{\mathrm{f}}$ Number of included samples: 40

${ }^{g}$ Number of included samples: 69

${ }^{\text {h }}$ Number of included samples: 74

${ }^{\mathrm{i}}$ Number of included samples: 57

${ }^{\mathrm{j}}$ Number of included samples: 63

${ }^{\mathrm{k}}$ Number of included samples: 47

${ }^{1}$ Number of included samples: 64

${ }^{\mathrm{m}}$ Number of included samples: 36

${ }^{\mathrm{n}}$ Number of included samples: 68

there was no deleterious effect from the multiplexing or from the use of a chaotropic agent on the conjugated beads. Nevertheless, the fluorescence intensity readings (which are proportional to the IgG antibody concentrations in the sample) in this avidity assay should remain within a predetermined interval (MFI between 100 and 7000) to ensure the consistency of the results. Furthermore, multiple dilutions of the same sample may be required since the antibody concentrations to different antigens in a sample may vary.

Herein, we found that children with pneumococcal disease present lower avidity of antibodies against most evaluated protein antigens in both acute and convalescent samples, compared to children without pneumococcal disease (Table 5). Similar results were found when comparing solely children with IPD with healthy controls (Table 2). To the best of our knowledge, the avidity of IgG against pneumococcal protein antigens in clinical settings has only once been evaluated previously, in a study testing the avidity of $\operatorname{IgG}$ against Ply, CbpA, and PspA in a group composed of 20 children with IPD and 20 healthy controls [25]. In that study, higher avidity was found in children with IPD in the convalescent phase of disease when compared to the control group. The results from previous studies evaluating the avidity of antibodies against capsular polysaccharides, however, have also found lower avidity in children with pneumococcal disease. For instance, children with recurrent respiratory infections presented lower avidity of IgG against capsular polysaccharides when compared to healthy controls, in a study evaluating the antibody levels against 12 pneumococcal serotypes [2]. Low avidity and opsonic activity have also been reported against the infecting serotype in children with IPD [4]. In this scenario, the presence of high-avidity antibodies against pneumococcal polysaccharides has been described as a protective factor against pneumococcal infection $[33,35,36]$. It is possible, therefore, that the higher avidity against pneumococcal proteins in the group of children without pneumococcal disease found herein may also be a determinant of protection against infection by this bacterium.

Herein, we did not find a statistically significant increase in IgG avidity between acute and convalescent serum samples. An increase in avidity against pneumococcal proteins has been reported by Ota et al. [25], who found lower avidity of IgG against Ply, CbpA, and PspA in the acute phase of disease in children with IPD compared to the convalescent phase of disease. Nevertheless, these differences did not reach statistical significance. It is possible that the small sample size from 

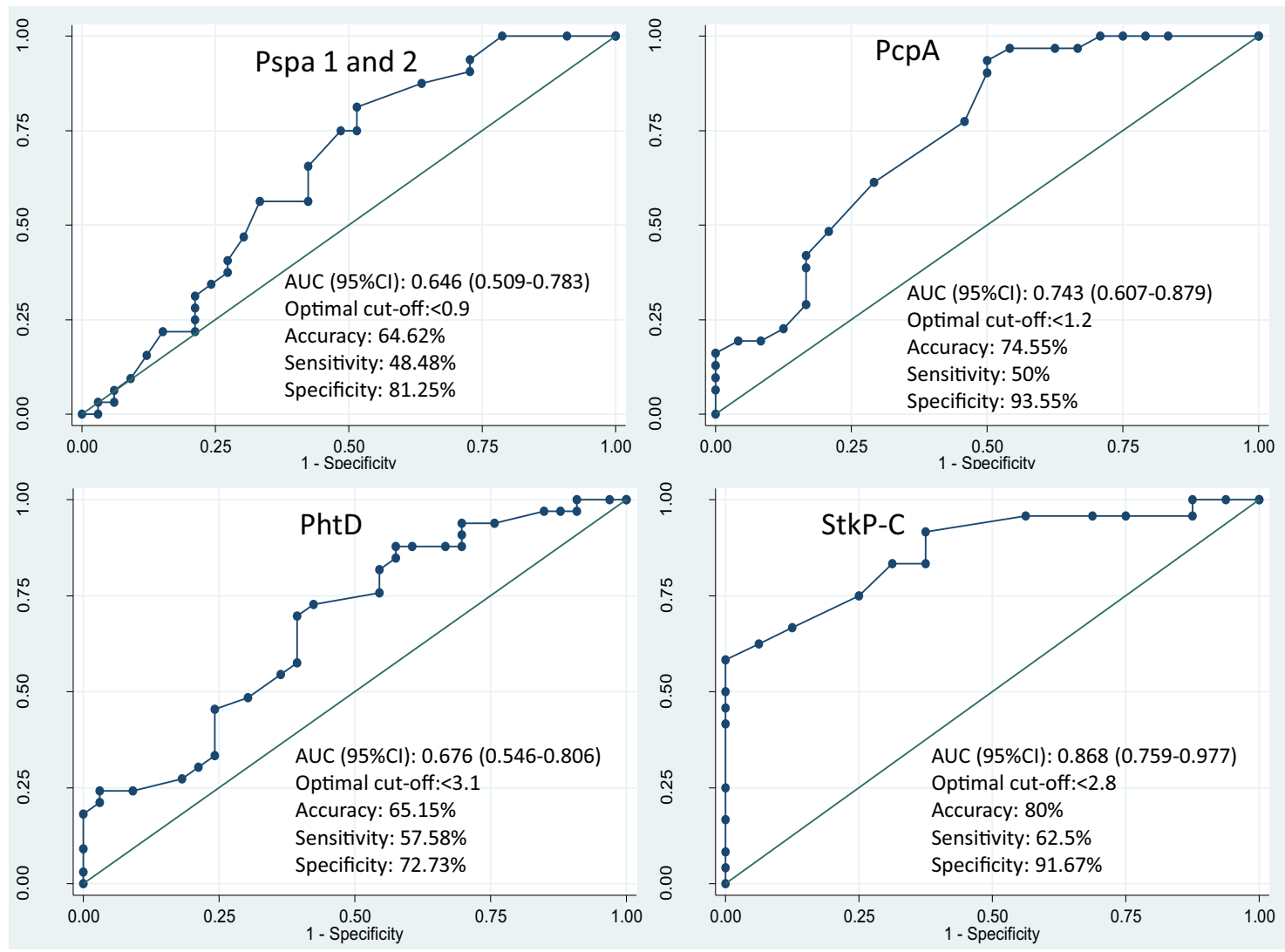

Fig. 4 Receiver operating characteristic (ROC) curves for the avidity indexes for IgG against PspA1 and 2, PcpA, PhtD, and StkP-C on the first serum sample. The number of valid values included in the analysis and optimal cut-off point for the diagnosis of pneumococcal disease with their respective accuracy, sensitivity, and specificity are shown in the graphs

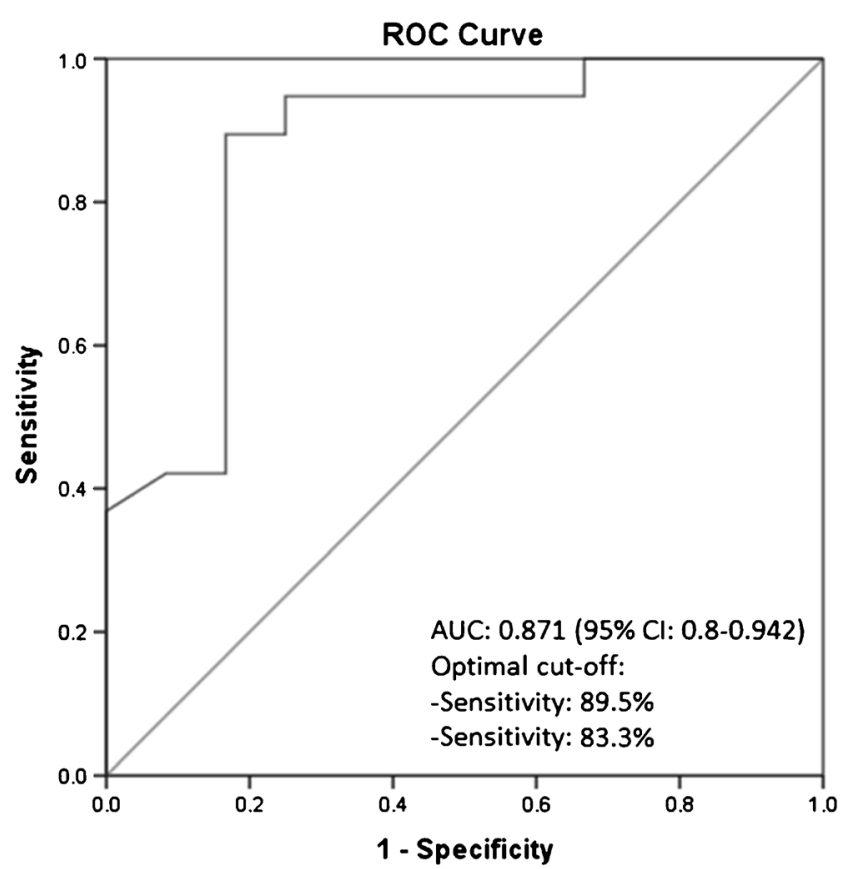

Fig. 5 Receiver operating characteristic (ROC) curves for the avidity for IgG against both PcpA and StkP-C for the first serum sample both our study and that from Ota et al. have prevented the detection of statistically significant increases in avidity between acute and convalescent samples, which would represent the maturation of antigen-specific antibodies as a response to exposure to pneumococcal antigens.

On the evaluation of antibody avidity as a diagnostic tool for pneumococcal disease, we found that different proteins had varying discriminative powers for the detection of infection caused by $S$. pneumoniae. Overall, antibodies to StkP-C and PcpA presented high accuracy and could be considered as a candidate for an avidity assay in clinical practice. Furthermore, the use of combinations of different antigens in avidity assays may increase the accuracy of the test for the diagnosis of pneumococcal disease in children, as we showed herein for a combined assay of PcpA and StkP-C. The use of avidity has the advantage of requiring only one serum sample to provide diagnostic information, compared to serological assays, which required paired samples. For instance, the avidity of IgG against pneumococcal polysaccharides was evaluated for diagnostic purposes by Fried et al. [2], who described a high discriminative power for avidity to distinguish between groups of children with recurrent bacterial 
Fig. 6 Comparison of the median difference between acute and convalescent samples among children with invasive pneumococcal disease, children with pneumococcal pneumonia, healthy children, and children with non-pneumococcal pneumonia
Median difference between acute and convalescent serum samples

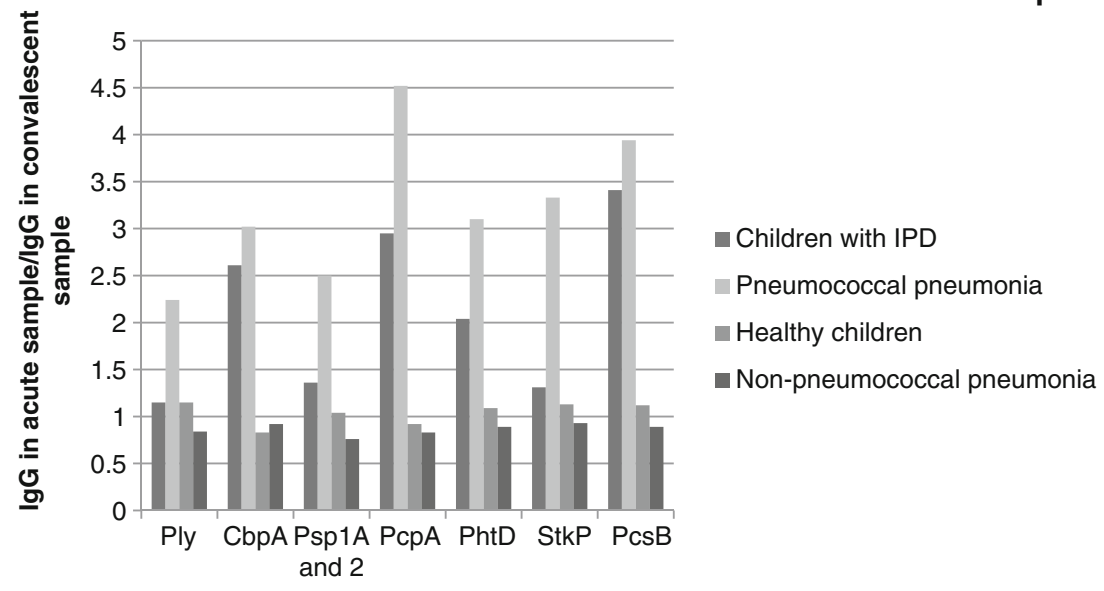

respiratory infections and healthy controls. Nevertheless, the adequate validation of avidity protocols and definition of cutoff points for the diagnosis of acute disease is still required, particularly for assays including pneumococcal proteins that have only recently been described. Herein, we presented a preliminary evaluation of the optimal cut-offs of avidity for the diagnosis of pneumococcal disease and found a large range of avidity indexes when the cut-off points were chosen based on the highest accuracy for each protein. This finding reinforces the need for an individualized validation for each protein antigen.

The limitations of this study should be noted. Firstly, there were important differences within the group of children without pneumococcal disease (i.e., between the subgroup of healthy children and the subgroup of children with CAP without serological response to $S$. pneumoniae), such as nationality, age, and sampling interval. However, when the avidity of IgG between the subgroups was evaluated, a difference between the subgroups was found only for PhtD. It is possible that the older age in the subgroup of healthy children may have contributed to the higher avidity found against PhtD due to the longer time of possible exposition to S. pneumoniae. Secondly, a considerable amount of samples were excluded from the analysis due to the detection of antibody levels outside the determined optimal range. Unfortunately, repetitions could not be performed for such samples due to material and time restrictions. It is important to emphasize, however, that this was a preliminary study aiming to standardize and apply the first avidity assay in multiplex against eight pneumococcal antigens, and the described protocol should be re-evaluated using a larger panel of patient samples. Secondly, we included samples of five children aged under 6 months of age, who could still be, theoretically, under the protection of maternal antibodies. It is important to note, however, that antibody increases against pneumococcal proteins have already been reported in children aged under 6 months in the setting of symptomatic respiratory infections, such as CAP and acute otitis media [20,37, 38]. Therefore, as young children can produce significant quantitative antibody responses despite the presence of maternal antibodies, we hypothesize that avidity should also be affected during pneumococcal infection. Thirdly, there was a decrease in the fluorescence readings for PcpA following treatment with $6 \mathrm{M}$ Sodium thiocyanate. Nevertheless, we still found a high correlation between beads conjugated with this antigen which were pretreated with Sodium thiocyanate or not (Fig. 2). Finally, we had no data on colonization of the included children by S. pneumoniae, and how this form of contact with the pneumococcus could affect the avidity of anti-protein IgG. It has been reported that children with social mixing with other children, a risk factor to pneumococcal colonization, had higher avidity of IgG against some pneumococcal serotypes than lone children [39]. The effect of colonization with S. pneumoniae on the avidity of antibodies against pneumococcal proteins should be the focus of future studies.

In conclusion, this was the first report of the development and validation of an avidity assay in multiplex using pneumococcal proteins, which was robust and had no deleterious effect from multiplexing. When applied to a clinical setting, the described assay was able to identify differences in avidity of anti-protein IgG between groups of children with and without pneumococcal disease, with lower avidity found in the group of children with pneumococcal disease. The avidity of antibodies against pneumococcal proteins may also be used as a diagnostic tool for pneumococcal infection, and the protein antigens StkP-C and PcpA should be considered for inclusion in such an assay.

Acknowledgements We thank Sanofi Pasteur (Lyon, France) for supplying PcpA and PhtD; Prof. Elaine Tuomanen at St. Jude Children's Research Hospital (Memphis, TN, USA) for supplying Ply, CbpA, and PspA1; Profs. Susan Hollingshead, David Briles, and Pat Coan at University of Alabama (Birmingham, AL, USA) for supplying PspA2; and Valneva Austria GmbH (Vienna, Austria) for supplying StkP-C and PcsB-N. 
Data availability statement The datasets used and/or analyzed during the current study are available from the corresponding author on reasonable request.

Funding This work was supported by: Bahia State Agency for Research Funding (FAPESB), Brazil; Brazilian Council for Scientific and Technological Development (CNPq), Brazil; Turku University Hospital Research Foundation, Finland; Rauno and Anne Puolimatka Foundation, Finland; Sohlberg Foundation, Finland.

\section{Compliance with ethical standards}

Conflict of interest The authors declare that they have no conflict of interest.

Ethical approval The use of the samples was approved by the Ethics Committee of the Federal University of Bahia in Brazil, the Ethics Committee of the National Institute for Health and Welfare in Finland (formerly National Public Health Institute), and the Ethics Committee of Satakunta Central Hospital, Pori, Finland.

Informed consent Written informed consent was obtained from legal guardians before recruitment.

\section{References}

1. O'Brien KL, Wolfson LJ, Watt JP, Henkle E, Deloria-Knoll M, McCall N, Lee E, Mulholland K, Levine OS, Cherian T; Hib and Pneumococcal Global Burden of Disease Study Team (2009) Burden of disease caused by Streptococcus pneumoniae in children younger than 5 years: global estimates. Lancet 374:893-902

2. Fried AJ, Altrich ML, Liu H, Halsey JF, Bonilla FA (2013) Correlation of pneumococcal antibody concentration and avidity with patient clinical and immunologic characteristics. J Clin Immunol 33:847-856

3. Ekström N, Ahman H, Palmu A, Grönholm S, Kilpi T, Käyhty H; FinOM Study Group (2013) Concentration and high avidity of pneumococcal antibodies persist at least 4 years after immunization with pneumococcal conjugate vaccine in infancy. Clin Vaccine Immunol 20:1034-1040

4. Oishi T, Ishiwada N, Matsubara K, Nishi J, Chang B, Tamura K, Akeda Y, Ihara T, Nahm MH, Oishi K; Japanese IPD Study Group (2013) Low opsonic activity to the infecting serotype in pediatric patients with invasive pneumococcal disease. Vaccine 31:845-849

5. Principi N, Esposito S (2011) Universal protein vaccines against Neisseria meningitidis serogroup B, Streptococcus pneumoniae and influenza. Hum Vaccin 7:905-912

6. van der Poll T, Opal SM (2009) Pathogenesis, treatment, and prevention of pneumococcal pneumonia. Lancet 374:1543-1556

7. Tai SS (2006) Streptococcus pneumoniae protein vaccine candidates: properties, activities and animal studies. Crit Rev Microbiol 32:139-153

8. Brooks-Walter A, Briles DE, Hollingshead SK (1999) The $p s p C$ gene of Streptococcus pneumoniae encodes a polymorphic protein, $\mathrm{PspC}$, which elicits cross-reactive antibodies to PspA and provides immunity to pneumococcal bacteremia. Infect Immun 67:65336542

9. Briles DE, Hollingshead S, Brooks-Walter A, Nabors GS, Ferguson L, Schilling M, Gravenstein S, Braun P, King J, Swift A (2000) The potential to use PspA and other pneumococcal proteins to elicit protection against pneumococcal infection. Vaccine 18:1707-1711
10. Croney CM, Coats MT, Nahm MH, Briles DE, Crain MJ (2012) PspA family distribution, unlike capsular serotype, remains unaltered following introduction of the heptavalent pneumococcal conjugate vaccine. Clin Vaccine Immunol 19:891-896

11. Khan MN, Sharma SK, Filkins LM, Pichichero ME (2012) PcpA of Streptococcus pneumoniae mediates adherence to nasopharyngeal and lung epithelial cells and elicits functional antibodies in humans. Microbes Infect 14:1102-1110

12. Khan MN, Pichichero ME (2012) Vaccine candidates PhtD and $\mathrm{PhtE}$ of Streptococcus pneumoniae are adhesins that elicit functional antibodies in humans. Vaccine 30:2900-2907

13. Adamou JE, Heinrichs JH, Erwin AL, Walsh W, Gayle T, Dormitzer M, Dagan R, Brewah YA, Barren P, Lathigra R, Langermann S, Koenig S, Johnson S (2001) Identification and characterization of a novel family of pneumococcal proteins that are protective against sepsis. Infect Immun 69:949-958

14. Giefing C, Meinke AL, Hanner M, Henics T, Bui MD, Gelbmann D, Lundberg U, Senn BM, Schunn M, Habel A, HenriquesNormark B, Ortqvist A, Kalin M, von Gabain A, Nagy E (2008) Discovery of a novel class of highly conserved vaccine antigens using genomic scale antigenic fingerprinting of pneumococcus with human antibodies. J Exp Med 205:117-131

15. Giefing-Kröll C, Jelencsics KE, Reipert S, Nagy E (2011) Absence of pneumococcal PcsB is associated with overexpression of LysM domain-containing proteins. Microbiology 157:1897-1909

16. Giefing C, Jelencsics KE, Gelbmann D, Senn BM, Nagy E (2010) The pneumococcal eukaryotic-type serine/threonine protein kinase StkP co-localizes with the cell division apparatus and interacts with FtsZ in vitro. Microbiology 156:1697-1707

17. Chen A, Mann B, Gao G, Heath R, King J, Maissoneuve J, Alderson M, Tate A, Hollingshead SK, Tweten RK, Briles DE, Tuomanen EI, Paton JC (2015) Multivalent pneumococcal protein vaccines comprising pneumolysoid with epitopes/fragments of $\mathrm{CbpA}$ and/or PspA elicit strong and broad protection. Clin Vaccine Immunol 22:1079-1089

18. Olafsdottir TA, Lingnau K, Nagy E, Jonsdottir I (2012) Novel protein-based pneumococcal vaccines administered with the Th1promoting adjuvant IC31 induce protective immunity against pneumococcal disease in neonatal mice. Infect Immun 80:461-468

19. Brooks WA, Chang LJ, Sheng X, Hopfer R; PPR02 Study Team (2015) Safety and immunogenicity of a trivalent recombinant PcpA, PhtD, and PlyD1 pneumococcal protein vaccine in adults, toddlers, and infants: a phase I randomized controlled study. Vaccine 33:4610-4617

20. Andrade DC, Borges IC, Ivaska L, Peltola V, Meinke A, Barral A, Käyhty H, Ruuskanen O, Nascimento-Carvalho CM (2016) Serological diagnosis of pneumococcal infection in children with pneumonia using protein antigens: a study of cut-offs with positive and negative controls. J Immunol Methods 433:31-37

21. Andrade DC, Borges IC, Laitinen H, Ekström N, Adrian PV, Meinke A, Barral A, Nascimento-Carvalho CM, Käyhty H (2014) A fluorescent multiplexed bead-based immunoassay (FMIA) for quantitation of IgG against Streptococcus pneumoniae, Haemophilus influenzae and Moraxella catarrhalis protein antigens. J Immunol Methods 405:130-143

22. Jiménez-Munguía I, van Wamel WJ, Olaya-Abril A, GarcíaCabrera E, Rodríguez-Ortega MJ, Obando I (2015) Proteomicsdriven design of a multiplex bead-based platform to assess natural $\mathrm{IgG}$ antibodies to pneumococcal protein antigens in children. $\mathrm{J}$ Proteome 126:228-233

23. Meriluoto M, Hedman L, Tanner L, Simell V, Mäkinen M, Simell S, Mykkänen J, Korpelainen J, Ruuskanen O, Ilonen J, Knip M, Simell O, Hedman K, Söderlund-Venermo M (2012) Association of human bocavirus 1 infection with respiratory disease in childhood follow-up study, Finland. Emerg Infect Dis 18:264-271 
24. Chen T, Tanner L, Simell V, Hedman L, Mäkinen M, Sadeghi M, Veijola R, Hyöty H, Ilonen J, Knip M, Toppari J, Simell O, Söderlund-Venermo M, Hedman K (2014) Diagnostic methods for and clinical pictures of polyomavirus primary infections in children, Finland. Emerg Infect Dis 20:689-692

25. Ota MO, Oluwalana C, Howie SR, Gomez M, Ogunniyi AD, Mendy-Gomez AL, Owolabi O, Mureithi MW, Townend J, Secka O, Antonio M, Sutherland JS, Adegbola RA (2011) Antibody and T-cell responses during acute and convalescent stages of invasive pneumococcal disease. Int J Infect Dis 15:e282-e288

26. Posfay-Barbe KM, Galetto-Lacour A, Grillet S, Ochs MM, Brookes RH, Kraehenbuhl JD, Cevey-Macherel M, Gehri M, Gervaix A, Siegrist CA (2011) Immunity to pneumococcal surface proteins in children with community-acquired pneumonia: a distinct pattern of responses to pneumococcal choline-binding protein A. Clin Microbiol Infect 17:1232-1238

27. Seiberling M, Bologa M, Brookes R, Ochs M, Go K, Neveu D, Kamtchoua T, Lashley P, Yuan T, Gurunathan S (2012) Safety and immunogenicity of a pneumococcal histidine triad protein $\mathrm{D}$ vaccine candidate in adults. Vaccine 30:7455-7460

28. Ogunniyi AD, Woodrow MC, Poolman JT, Paton JC (2001) Protection against Streptococcus pneumoniae elicited by immunization with pneumolysin and CbpA. Infect Immun 69:5997-6003

29. Orihuela CJ, Mahdavi J, Thornton J, Mann B, Wooldridge KG, Abouseada N, Oldfield NJ, Self T, Ala'Aldeen DA, Tuomanen EI (2009) Laminin receptor initiates bacterial contact with the blood brain barrier in experimental meningitis models. J Clin Invest 119: 1638-1646

30. Borges IC, Andrade DC, Cardoso MR, Toppari J, Vähä-Mäkilä M, Ilonen J, Knip M, Hyöty H, Veijola R, Simell O, Jartti T, Käyhty H, Ruuskanen O, Nascimento-Carvalho CM (2016) Natural development of antibodies against Streptococcus pneumoniae, Haemophilus influenzae, and Moraxella catarrhalis protein antigens during the first 13 years of life. Clin Vaccine Immunol 23: 878-883

31. Pullen GR, Fitzgerald MG, Hosking CS (1986) Antibody avidity determination by ELISA using thiocyanate elution. J Immunol Methods 86:83-87
32. Ekström N, Väkeväinen M, Verho J, Kilpi T, Käyhty H (2007) Functional antibodies elicited by two heptavalent pneumococcal conjugate vaccines in the Finnish Otitis Media Vaccine Trial. Infect Immun 75:1794-1800

33. Anttila M, Voutilainen M, Jäntti V, Eskola J, Käyhty H (1999) Contribution of serotype-specific IgG concentration, IgG subclasses and relative antibody avidity to opsonophagocytic activity against Streptococcus pneumoniae. Clin Exp Immunol 118:402407

34. Schlesinger Y, Granoff DM (1992) Avidity and bactericidal activity of antibody elicited by different Haemophilus influenzae type b conjugate vaccines. The Vaccine Study Group. JAMA 267:14891494

35. Usinger WR, Lucas AH (1999) Avidity as a determinant of the protective efficacy of human antibodies to pneumococcal capsular polysaccharides. Infect Immun 67:2366-2370

36. Musher DM, Phan HM, Watson DA, Baughn RE (2000) Antibody to capsular polysaccharide of Streptococcus pneumoniae at the time of hospital admission for pneumococcal pneumonia. J Infect Dis 182:158-167

37. Rapola S, Kilpi T, Lahdenkari M, Mäkelä PH, Käyhty H (2001) Antibody response to the pneumococcal proteins pneumococcal surface adhesin A and pneumolysin in children with acute otitis media. Pediatr Infect Dis J 20:482-487

38. Andrade DC, Borges IC, Adrian PV, Meinke A, Barral A, Ruuskanen O, Käyhty H, Nascimento-Carvalho CM (2016) Effect of pneumococcal conjugate vaccine on the natural antibodies and antibody responses against protein antigens from Streptococcus pneumoniae, Haemophilus influenzae and Moraxella catarrhalis in children with community-acquired pneumonia. Pediatr Infect Dis J 35:683-689

39. Salt P, Banner C, Oh S, Yu LM, Lewis S, Pan D, Griffiths D, Ferry B, Pollard A (2007) Social mixing with other children during infancy enhances antibody response to a pneumococcal conjugate vaccine in early childhood. Clin Vaccine Immunol 14:593-599 